\title{
O VIVENCIAL DOS ENFERMEIROS NO PROGRAMA DE TRANSPLANTE DE FÍGADO DE UM HOSPITAL PÚBLICO*
}

Maria Cristina Komatsu Braga Massarollo** Paulina Kurcgant***

MASSAROLLO, M.C.K.B.; KURCGANT, P. O vivencial dos enfermeiros no programa de transplante de fígado de um hospital público. Rev.latino-am.enfermagem, Ribeirão Preto, v. 8, n. 4, p. 66-72, agosto 2000.

Este estudo teve como objetivo desvelar a vivência dos enfermeiros no programa de transplante de fígado de um hospital público. Para compreender o vivencial dos enfermeiros, optou-se por realizar uma pesquisa qualitativa, utilizando a vertente fenomenológica, segundo a modalidade "estrutura do fenômeno situado". As proposições que emergiram revelaram que a essência do fenômeno "vivenciar a prestação da assistência de enfermagem aos pacientes do programa de transplante de figado de um hospital público" foi desvelada como o viver uma situação que oculta necessidades, dificuldades, contradições, conflitos e satisfação.

UNITERMOS: transplante de figado, enfermagem

\section{INTRODUÇÃO}

O transplante de fígado é uma modalidade terapêutica que possibilita a reversão do quadro terminal de um paciente com doença hepática. É utilizado como recurso para os pacientes portadores de lesão hepática irreversível, quando mais nenhuma outra forma de tratamento se encontra disponível $e^{3,4,6,8,15,16,17,18}$.

$\mathrm{Na}$ maioria dos casos, os pacientes que têm indicação para transplante de fígado são portadores de uma doença crônica, de evolução progressiva e irreversível, com um longo percurso em unidades de tratamento intensivo ${ }^{8}$. Esses pacientes, de forma geral, apresentam um complexo conjunto de características e complicações, envolvendo aspectos, desde os relativos à esfera biológica, até problemas psicológicos, sociais e econômicos.

Os candidatos a esse procedimento possuem uma qualidade de vida ruim e vivem na perspectiva de morte iminente. Assim, a inclusão do paciente na lista de espera do transplante hepático representa a possibilidade de viver, a possibilidade de mudar de vida, a possibilidade de ser feliz. Entretanto, a espera prolongada por um órgão para ser transplantado propicia o aparecimento de uma série de complicações para o paciente, tornando-o de alto risco para o procedimento e sendo responsável por um número considerável de óbitos de pacientes que estão na fila de espera. Dessa forma, a taxa de mortalidade para os potenciais receptores é alta, fazendo com que, para muitos, a morte preceda a disponibilidade de um órgão para ser transplantado.

Nesse contexto, a possibilidade de acompanhar a evolução do transplante de fígado e as situações a ele relacionadas, vivenciadas pelos pacientes, despertou o interesse em se conhecer como era a organização do trabalho, a atuação da enfermeira e a assistência de enfermagem prestada aos pacientes do programa de transplante hepático, acreditando-se ser essa uma área nova, com muitas possibilidades e oportunidades para a atuação da enfermagem. Essas interrogações estimularam o conhecimento das atividades desenvolvidas pelos enfermeiros e a assistência prestada aos pacientes, o que foi conseguido através da realização de estágio e da participação em congressos, cursos e aulas que abordavam o tema.

À medida que se ampliava o conhecimento a respeito dos pacientes, intensificavam-se as inquietações, percebendo-se que essa vivência era bastante difícil para eles e que os enfermeiros tinham um papel relevante no enfrentamento dessas situações.

\footnotetext{
* Extraído da tese apresentada à Escola de Enfermagem da Universidade de São Paulo, para a obtenção do título de Doutor em Enfermagem

** Enfermeira. Professor Doutor do Departamento de Orientação Profissional da Escola de Enfermagem da Universidade de São Paulo

*** Enfermeira. Orientadora. Professor Titular do Departamento de Orientação Profissional da Escola de Enfermagem da Universidade de São Paulo
} 
Assim, considerando-se o aumento da demanda pelo procedimento, a necessidade de conhecimentos específicos e a falta de referências bibliográficas, ficou evidenciado que a temática necessitava ser analisada no concreto dessa prática.

O interesse em desvelar o fenômeno "vivência do enfermeiro na prestação da assistência de enfermagem a pacientes integrantes de um programa de transplante hepático", motivou a realização do presente estudo, que objetivou:

- Desvelar a vivência dos enfermeiros do programa de transplante de fígado, de um hospital público, segundo suas percepções.

- Desvelar como se dá a assistência de enfermagem aos pacientes integrantes desse programa.

\section{TRAJETÓRIA METODOLÓGICA NA PESQUISA}

\subsection{A escolha da trajetória metodológica}

Para a realização deste estudo, optou-se por realizar uma pesquisa qualitativa, utilizando a vertente fenomenológica, modalidade estrutura do fenômeno situado, segundo o referencial de MARTINS \& BICUDO $^{12}$

Com a adoção do método fenomenológico na condução da pesquisa, buscou-se desvelar o significado que os enfermeiros que prestam assistência de enfermagem a pacientes de um programa de transplante hepático, atribuem a essa assistência. Com o estudo, assim encaminhado, pretendeu-se o desocultamento dos atributos ocultos, quando interrogado o fenômeno investigado.

\subsection{A fenomenologia como vertente metodológica}

A fenomenologia é o estudo das essências e dos significados articulados nos discursos. É uma volta ao mundo vivido, ao mundo da experiência, que para HUSSERL $^{7}$ é o fundamento de todas as ciências. Tem como objetivo precípuo a investigação direta e a descrição de fenômenos que são experienciados pela consciência, sem preocupação sobre sua explicação causal, livre de preconceitos e pressupostos ${ }^{11,13}$. Visa redescobrir o que são as coisas nelas mesmas, tais como se mostram ou aparecem à consciência perceptiva ${ }^{2}$.

Assim, no caminhar fenomenológico, a questão central é a reflexão sobre o mundo-vida, que pressupõe um mundo exterior do qual o sujeito deve estar ciente e que lhe é revelado através da consciência. Para a fenomenologia não pode haver consciência desvinculada de um mundo, como não existe mundo sem que haja consciência para percebê-lo. Mediante a intencionalidade da consciência todos os atos, os gestos, os hábitos, qualquer ação humana tem um significado. Para a fenomenologia não há um fenômeno em si, mas há um fenômeno para o ser que lhe dá um significado ${ }^{1,13}$. Dessa forma, consciência e objeto são entidades indissociáveis que coexistem inter-relacionadas, já que na ausência de uma a outra deixa de existir.

Segundo MARTINS \& BICUDO $^{12}$, a fenomenologia descreve a experiência do Homem tal como ela é, e não segundo as proposições préestabelecidas pelas ciências naturais. Para se conhecer a experiência humana, não se pode adotar os mesmos procedimentos pelos quais se conhece a realidade física ou biológica. Faz-se necessário um método próprio, que focalize a experiência vivida e sua significação.

$\mathrm{O}$ mundo fenomenológico não é imaginário e, sim, aquilo que o Homem percebe e vive. Não é o do ser puro, mas o sentido que aparece na intersecção das experiências passadas e presentes de cada um e na intersecção delas com a dos outros, contemplando a subjetividade e a intersubjetividade envolvidas nessas relações ${ }^{14}$.

É preciso considerar que "para que o fenômeno se mostre não basta vivê-lo, pois na imersão a amplitude de visão se restringe. A compreensão exige, pois, transcender esta perspectiva e espreitar as diferentes possibilidades através do ver e do sentir do outro" ${ }^{\text {. }}$.

Para a pesquisa, a fenomenologia é uma forma particular de fazer ciência, que substitui as correlações estatísticas pelas descrições individuais e as conexões causais por interpretações oriundas das experiências vividas. Apresenta-se como ciência descritiva, rigorosa, concreta, que mostra e explicita, que se preocupa com a essência do vivido ${ }^{2}$.

Assim, na pesquisa fenomenológica os dados não são coletados como se fossem fatos. Não se busca uma relação de causalidade, mas significados atribuídos ao fenômeno estudado. Ao concentrar-se nos significados, o pesquisador está preocupado com aquilo que os eventos significam para os sujeitos da pesquisa. $\mathrm{O}$ número de sujeitos para a pesquisa, na vertente fenomenológica, deve ser estipulado pelo pesquisador, considerando que as unidades significativas na descrição tenham uma variação que possibilite ver o que é essencial ${ }^{12}$.

O pesquisador, segundo MARTINS \& BICUDO $^{12}$, não descarta a sua experiência mas soma com a experiência que outros têm do fenômeno estudado, para compreender cada vez mais a sua própria concepção do fenômeno, e evoluí-la pela articulação dela com a dos sujeitos pesquisados. O pesquisador vai iniciar o seu trabalho apenas interrogando o fenômeno, mas isso não 
exclui que ele tenha um pensar ${ }^{12,13}$

Para o exame das experiências vividas e dos significados a elas atribuídos, a fenomenologia como método de pesquisa fica caracterizada pela descrição, redução e compreensão ${ }^{5,11,12}$.

A descrição fenomenológica é o primeiro momento da trajetória na pesquisa e resulta da relação dos sujeitos com o pesquisador, sendo, portanto, o discurso obtido, constituído de elementos estruturais do fenômeno a ser desvelado, que representa o que está articulado na inteligibilidade do sujeito e que se mostra através da fala ${ }^{12}$.

A redução fenomenológica, como segundo momento da trajetória, tem como objetivo determinar e selecionar as partes da descrição que são consideradas essenciais. Consiste, então, na busca, pelo pesquisador, das proposições que lhe são significativas e que permitem compreender aquilo que é essencial ao fenômeno em questão, a partir do discurso do sujeito. É um procedimento planejado para retornar-se à experiência vivida pelos sujeitos, deixando de lado qualquer crença, teoria ou explicação a priori. Esse momento é chamado de epoché ${ }^{13}$.

A compreensão fenomenológica ocorre quando as expressões ingênuas do discurso são substituídas por expressões próprias do pesquisador, que representam aquilo que está sendo buscado. É um pensar sobre os significados, contemplado pela análise ideográfica, e nomotética ${ }^{12}$

A análise ideográfica diz respeito à análise do discurso individual. É a análise da ideologia que permeia as descrições ingênuas do sujeito ${ }^{12}$.

Entretanto, a estrutura individual reflete apenas um exemplo do fenômeno. O movimento da passagem do individual para o geral dá-se em direção à estrutura geral do fenômeno que está sendo estudado, o que é buscado com a análise nomotética, que é uma ação reflexiva em busca da estrutura essencial do fenômeno que é resultante da compreensão das convergências e divergências que se mostram nos casos individuais ${ }^{12}$.

\subsection{O método fenomenológico na pesquisa}

\subsubsection{A região de inquérito e o fenômeno situado}

O fenômeno só pode se mostrar quando situado, quando interrogado. Como fenômeno, é perspectiva, diverge em vários aspectos, precisa ser situado em uma região de inquérito, que é a região de perplexidade, a região onde o fenômeno vai ser interrogado, onde o sujeito está vivenciando o fenômeno.

A região de inquérito, no presente estudo, é a situação de prestar assistência de enfermagem a pacientes do programa de transplante hepático, da Unidade de Fígado do Hospital das Clínicas da Faculdade de Medicina da Universidade de São Paulo (UF)****, do município de São Paulo, compreendendo o transplante como um processo, que pode ser dividido em quatro períodos consecutivos: a inclusão do paciente na lista de espera, o preparo e a espera para a realização do procedimento, o transplante propriamente dito e o período pós-operatório. Os sujeitos que vivenciam o fenômeno e, dessa forma, partícipes do estudo, são enfermeiros que assistem ao paciente em alguma fase do processo do transplante hepático, seja durante a internação hospitalar ou no ambulatório, tanto no pré, como no pós-transplante. Os enfermeiros que prestam assistência ambulatorial são os mesmos que atuam no trans-operatório. Assim, essa instituição foi escolhida intencionalmente, na busca de um universo que possibilitasse a captação do fenômeno "vivenciar a prestação da assistência de enfermagem a pacientes integrantes de um programa de transplante hepático".

\subsubsection{A obtenção das descrições}

Para a coleta de dados, após o aceite da instituição, a pesquisadora entrou em contato com os enfermeiros participantes do programa de transplante hepático, quando foi explicado o objetivo da pesquisa. Nessa ocasião, foi considerado o interesse dos mesmos em participar do estudo, sendo garantido o anonimato quanto à participação. Não houve recusa por parte dos enfermeiros. Assim, as entrevistas foram realizadas, em data, local e horário, segundo a preferência de cada um. Com elas pretendeu-se conseguir descrições detalhadas das vivências dos entrevistados, sem, contudo, produzir estímulos pré-categorizados para respostas desejadas. As descrições espontâneas dos sujeitos foram imprescindíveis para a compreensão de seus mundosvidas.

As entrevistas foram realizadas pela pesquisadora, com o auxílio de um gravador e transcritas em sua totalidade para análise de seu conteúdo. Alguns enfermeiros referiram não se sentir à vontade frente ao gravador, sendo, então, o registro dessas entrevistas feito integralmente, por escrito, durante a realização das mesmas, na presença do entrevistado.

Procurou-se fazer uma abordagem livre de juízo de valor, apresentando tópicos relevantes e significativos à captação do fenômeno "vivenciar a prestação da assistência de enfermagem a pacientes integrantes do programa de transplante hepático, de um hospital público", de forma não restritiva, tendo sido feitas

**** Identificação feita por solicitação do Serviço 
perguntas abertas que orientassem o pensamento e a descrição dos sujeitos, deixando-os falar livremente, não sendo pré-determinado o tempo de duração de cada entrevista.

Assim, os discursos foram coletados segundo as seguintes questões norteadoras "Qual a sua vivência como enfermeiro atuante do programa de transplante hepático?" e "Como se dá a assistência de enfermagem aos pacientes do programa de transplante hepático, desde a inclusão na lista de espera até os controles ambulatoriais tardios?"

O número de enfermeiros, independentemente do cargo ou função exercida, não foi definido a priori, pois segundo o método adotado, a análise das descrições foi sendo realizada até o momento em que ocorresse a invariância do fenômeno, ou seja, o desocultamento da essencialidade do fenômeno investigado. Assim, considerou-se que a partir do momento que houvesse a repetitividade nos discursos, as descrições seriam suficientes para o desvelamento do fenômeno 9 . Dessa forma, foram coletados 18 discursos, dos quais 11 passaram a ser trabalhados, ao constatar-se que seriam suficientes para responder à interrogação proposta.

\subsubsection{O momento da análise}

Para análise do conteúdo das entrevistas, seguiuse os momentos metodológicos definidos por MARTINS \& BICUDO $^{12}$, que consideram como momentos do método da análise qualitativa do fenômeno situado: o sentido do todo, a discriminação das unidades de significado, as transformações das expressões do sujeito em linguagem do pesquisador e a síntese das unidades de significado transformadas em proposição. Esses autores referem ser importante lembrar que a análise das descrições não compreende etapas rígidas a serem mecanicamente seguidas pelo pesquisador, mas representa o caminho para chegar-se à compreensão.

Os procedimentos descritos a seguir foram feitos para cada um dos discursos:

\section{- Análise ideográfica}

Para analisar os dados obtidos, os discursos foram enumerados de I a XI, lidos por inteiro, atenta e criteriosamente, mas sem interpretação, com a finalidade de apreender-se o sentido global do discurso (epoché).

Em leituras posteriores buscou-se, nas descrições de cada discurso, a presença evidente da essencialidade da prestação da assistência de enfermagem ao paciente vivenciando o transplante de fígado. Pela impossibilidade de analisar-se simultaneamente os depoimentos na sua totalidade, tornou-se necessário dividi-los em unidades de significado. Essas unidades de significado emergiram das descrições, a partir das mudanças de significado das situações descritas pelos enfermeiros.
Após a obtenção das unidades de significado procedeu-se à redução fenomenológica, quando as expressões cotidianas dos enfermeiros foram transformadas na linguagem da pesquisadora. Essas transformações ocorreram pela reflexão e pela variação imaginativa e são necessárias para que o pesquisador possa elucidar o que está oculto nas descrições ingênuas feitas pelos sujeitos ao se expressarem.

Assim, analisou-se cada situação, atentamente, tentando reconhecer o seu sentido, descobrindo uma significação mais ampla e desprovida de ingenuidade, que contemplasse o implícito, as diferenças e as correlações existentes em cada discurso. Tentou-se penetrar no cotidiano, onde a assistência de enfermagem prestada aos pacientes de um programa de transplante foi descrita, buscando-se a unidade e a consistência das diversas experiências relatadas.

Em seguida, buscou-se identificar e agrupar as unidades de significado interpretadas que apresentavam um tema comum. Desse agrupamento evidenciaram-se três diferentes temas ou categorias, que, pelo seu conteúdo, foram assim denominados: O SERVIÇO DE ENFERMAGEM, que incluiu a estrutura e a dinâmica; A EQUIPE DE ENFERMAGEM, que abordou a capacitação, a responsabilidade, a (des)integração entre os profissionais, a (des)motivação, a ansiedade, o espaço ocupado, a proposta e o significado do procedimento e A ASSISTÊNCIA DE ENFERMAGEM. Cabe esclarecer que (des)motivação e (des)integração referem-se tanto à motivação e desmotivação, como à integração e desintegração, respectivamente.

As unidades de significado foram agrupadas com a finalidade de organizar as articulações do discurso, formando núcleos de pensamento, que foram sintetizados e tematizados conforme várias perspectivas que emergiram do "ser enfermeiro de um programa de transplante hepático".

- Análise nomotética

Após a análise ideográfica de cada descrição, as unidades de significado interpretadas foram submetidas à análise nomotética. Para proceder à análise nomotética, preliminarmente, foi feito um agrupamento de todas as unidades de significado interpretadas dos onze discursos, dentro de suas respectivas categorias.

Buscou-se, nas unidades de significado interpretadas, agora visualizadas como um todo, identificar as idéias gerais nelas contidas, submetendoas a uma profunda reflexão para compreender as convergências e divergências encontradas nas descrições e expressando-as em uma linguagem mais concisa.

Seguindo-se a trajetória fenomenológica, o 
último passo constituiu uma síntese que integrou as idéias gerais desveladas da estrutura do fenômeno situado.

\section{CONSTRUINDO OS RESULTADOS}

O fenômeno desvelado nesta pesquisa é a vivência dos enfermeiros no programa de transplante de fígado, de um hospital público, que foi desocultada e compreendida a interrogação existente inicialmente.

Experienciar a assistência de enfermagem prestada aos pacientes de um programa de transplante hepático, de um hospital público, revela que o quantitativo e o qualitativo de pessoal não são determinados pelas necessidades decorrentes das atividades desenvolvidas, não havendo estrutura organizacional formalmente estabelecida para esse programa.

O processo de trabalho vigente, devido à carga horária e à dinâmica de trabalho do enfermeiro, dificulta o planejamento de suas atividades pessoais e profissionais, a realização de trabalhos científicos e a participação em cursos. Esse esquema de trabalho requer grande disponibilidade do profissional, sendo, esta, imprescindível para que ele possa continuar atuando nesse tipo de atividade. O conhecimento técnico e a organização do serviço, decorrentes do aumento do número de transplantes, vêm facilitando a atuação do enfermeiro.

O ambiente na unidade de internação de pacientes transplantados é muito estressante, tenso e de alto nível de exigência. $\mathrm{O}$ enfermeiro sofre cobrança, tanto da parte da equipe médica, como da enfermagem, sendo, muitas vezes, imputadas à enfermagem as intercorrências ocorridas com o paciente nessa Unidade.

A assistência ao paciente transplantado é altamente especializada, requerendo a atuação do enfermeiro nas diversas fases do processo e exigindo pessoal com capacitação específica. O enfermeiro assume grande responsabilidade na delegação de atividades ao auxiliar de enfermagem, pois esses pacientes necessitam de cuidados mais complexos do que outros pacientes, além de atenção e orientação específicas. Devido à própria situação vivenciada, os pacientes necessitam ter alguém próximo a eles, durante o período de internação.

As orientações, relativas ao transplante, nem sempre são compreendidas ou assimiladas pelos pacientes. Sendo assim, eles nem sempre têm o conhecimento necessário a respeito do tratamento a que estão sendo submetidos e das possibilidades de evolução, após o procedimento cirúrgico.

A orientação de alta é dada no momento da saída do paciente do hospital, não sendo aproveitado o período de internação para essas orientações. Nessa ocasião, são dadas muitas orientações ao mesmo tempo, com o agravante de não serem dadas por escrito, dificultando a compreensão do paciente e propiciando a ocorrência de erros. As orientações de alta não são padronizadas e, para tanto, são consideradas as condições e as necessidades do paciente e o critério de cada enfermeiro.

A assistência de enfermagem prestada é predominantemente técnica, não sendo, esse aspecto, gerador de dificuldades para os enfermeiros. As necessidades de natureza psicológica, que são comumente apresentadas pelos pacientes transplantados, nem sempre são atendidas como os pacientes desejam e necessitam.

Quanto ao relacionamento interpessoal, o número de pacientes a serem assistidos, o grau de dependência dos pacientes e a falta de disponibilidade do enfermeiro para prestar a assistência solicitada e necessária fazem com que o paciente receba, algumas vezes, do pessoal de enfermagem, o rótulo de "chato". Por outro lado, em outras vezes, o relacionamento dos enfermeiros com os pacientes, extrapola o relacionamento profissional, tornando-se uma relação de amizade.

Nos aspectos psicológicos, os pacientes do programa de transplante apresentam grande ansiedade e carência afetiva. A ansiedade também é apresentada pelos familiares. São causas de ansiedade a difícil trajetória do paciente hepatopata; o medo; a incerteza da evolução; a possibilidade de rejeição do órgão transplantado; a necessidade de medicação para o resto da vida; o período incerto de espera para a realização do transplante; a impossibilidade de realização do procedimento cirúrgico, após o paciente ter sido chamado para isso e o retardo da alta pelo surgimento de complicações. A falta de atividade do paciente, durante o período de internação, o fato de saber que tem um órgão que não lhe pertence e que uma pessoa teve que morrer para que ele pudesse viver parecem aumentar a carência afetiva. Para não agravar a situação, o paciente e os familiares não ficam sabendo quem foi o doador do órgão transplantado.

O período de espera, para os pacientes que aguardam o transplante, é de incerteza, provocando a ocorrência de riscos e transtornos. A adoção do critério "ordem de inclusão na lista de espera", previsto na Lei dos Transplantes, será um fator de facilitação.

$\mathrm{O}$ aspecto psicológico influi na evolução do paciente e a fé na sua boa evolução parece interferir no sucesso do transplante.

Quanto à assistência de enfermagem, a fragmentação faz com que o enfermeiro perca a noção do todo. Os enfermeiros, que prestam assistência ao paciente durante o período de internação, desconhecem a assistência pré e pós-transplante prestada no ambulatório. A falta de continuidade do trabalho e de integração entre os diferentes agentes não asseguram aos pacientes o recebimento das orientações necessárias e propiciam o recebimento de orientações repetitivas e 
cansativas. Os enfermeiros consideram que há necessidade de organização e entrosamento intra e inter equipes que participam do programa de transplante.

Nesse vivencial, a desmotivação dos enfermeiros no trabalho interfere no desenvolvimento das atividades. O trabalho é considerado frustrante e deprimente, pelo difícil relacionamento existente entre os profissionais, por ser imputado à enfermagem as falhas ocorridas na Unidade de Internação e pelo fato de não ser permitido ao profissional dar uma contribuição maior ao programa de transplante. $\mathrm{O}$ momento de atuação do enfermeiro interfere no seu envolvimento com o programa de transplante, mas, em geral, os enfermeiros consideram gratificante trabalhar com pacientes transplantados, considerando, também, o transplante, uma experiência nova, uma oportunidade que não se tem em qualquer lugar, uma possibilidade de desenvolvimento profissional, uma contribuição para a sociedade e motivo de orgulho para o profissional. Além disso, consideram, também, que a enfermagem está conquistando seu espaço no programa de transplante, sendo considerado, ainda, que o enfermeiro é importante na equipe de transplante, tanto na coordenação como na prestação da assistência ao paciente.

A frustração dos enfermeiros, quando ocorre, é devida não só a problemas administrativos e organizacionais, mas, também, à má evolução do paciente. A má evolução e o sofrimento dos pacientes são os aspectos negativos do transplante, que tornam difícil o vivencial do profissional, sugerindo a necessidade de ser trabalhado o aspecto emocional dos que atuam no programa.

O significado do transplante de fígado é contraditório para o enfermeiro. Ao mesmo tempo que considera o procedimento como sendo a possibilidade de viver do paciente, a esperança de uma vida melhor, percebe-o, também, como causa de sofrimento e morte. A situação vivenciada pelo enfermeiro leva-o a acreditar que não faria o transplante, caso necessitasse. Tem dificuldade em lidar com doador e receptor porque "a desgraça de um é a alegria de outro", gerando insegurança para posicionar-se frente aos transplantes.

Outro ponto de conflito para o enfermeiro é o fato de, no transplante, ser feito grande investimento para benefício de poucos, mas, que esses, ele reconhece, não teriam chance de sobrevivência, sem a realização do procedimento.

\section{SÍNTESE}

As proposições emergentes revelaram que o fenômeno "vivência do enfermeiro na prestação da assistência de enfermagem a pacientes integrantes de um programa de transplante de fígado" oculta necessidades, dificuldades, contradições, conflitos e satisfação sentidos pelos enfermeiros. Revelaram, também, que a assistência de enfermagem é altamente especializada e predominantemente técnica, sendo necessário haver maior integração entre os profissionais atuantes nesse programa.

\section{NURSING PERCEPTIONS IN THE LIVER TRANSPLANT PROGRAM OF A PUBLIC HOSPITAL IN BRAZIL}

The aim of this study was to uncover the experience lived by nurses working in the liver transplant program of a public hospital. In order to understand the nurse's experience, a qualitative research based on the "situated-phenomenon structure" was designed. The propositions obtained showed that the essence of the phenomenon "living the experience of nursing assistance to patients in the liver transplant program of a public hospital" was uncovered as living a situation which hides needs, difficulties, contradictions, conflicts and satisfaction.

KEY WORDS: liver transplantation, nursing

\section{LA VIVENCIA DE LOS ENFERMEROS EN EL PROGRAMA DE TRANSPLANTE DE HÍGADO DE UN HOSPITAL PÚBLICO}

Este estudio tuvo como objetivo el revelar la vivencia de los enfermeros en el programa de transplante de hígado de un hospital público. Para comprender las vivencias de los enfermeros se optó por realizar una investigación cualitativa, según la modalidad de "estructura del fenómeno situado". Las proposiciones que emergieron revelaron que la esencia del fenómeno, "vivenciar el dar asistencia de enfermería a los pacientes del programa de transplante de hígado de un hospital público", fue revelado como el vivir una situación que oculta necesidades, dificultades, contradicciones, conflictos y satisfacción. 
REFERÊNCIAS BIBLIOGRÁFICAS

01.BICUDO, M.A.V. Prefácio. In: MARTINS, J.; BICUDO, M.A.V. Estudos sobre existencialismo, fenomenologia e educação. São Paulo: Moraes, 1983. p. 7-16.

02. CAPALBO, C. Fenomenologia e educação. Forum Educ., v. 14, n. 3, p. 41-61,1990.

03. D'ANDREA, L.H. et al. Liver transplantation: an OR nurse's perspective. Today's O.R. Nurse, v. 14, n. 2, p. 33- 41, 1992.

04. DUDEK, C.N.; ROBINSON, L.C. Hepatic transplant - the last hope for some patients. Today's OR Nurse, v. 8, n. 1, p. 21- 4, 1988.

05. FRANÇA, C. Psicologia fenomenológica: uma das maneiras de se fazer. Campinas: UNICAMP, 1989.

06. GRUPPI, L.A. et al. Liver transplantation: key nursing diagnoses. Dimens. Crit. Care Nurs., v. 9, n. 5, p. 272-9, 1990.

07. HUSSERL, E. A idéia de fenomenologia. Lisboa: Setenta, 1986.

08. JENKINS, R.L. et al. Transplante hepático. Clín. Cir. Am. Norte, v. 65, n. 1, p. 107-26, 1985.

09. KEEN, E. Introdução à psicologia fenomenológica. Rio de Janeiro: Interamericana, 1979.

10. MACHADO, O.V. de M. Ensino de ciências na escola de $1^{\mathbf{0}}$ grau: visão de ciência veiculada pelos alunos. São Paulo, 1989. 148 p. Dissertação (Mestrado) - Pontifícia Universidade Católica de São Paulo.
11. MARTINS, J. Um enfoque fenomenológico do currículo: educação como poíesis. São Paulo: Cortez, 1992.

12. MARTINS, J.; BICUDO, M.A.V. A pesquisa qualitativa em fenomenologia: fundamentos e recursos básicos. São Paulo: Moraes/EDUC, 1989.

13. MARTINS, J. et al. A fenomenologia como alternativa metodológica para pesquisa: algumas considerações. Rev. Esc. Enfermagem USP, v. 24, n. 1, p. 139-47, 1990.

14.MERLEAU-PONTY, M. Fenomenologia da percepção. Rio de Janeiro: Freitas Bastos, 1971.

15.MORI, V.; PINTO, M.C.M. Assistência de enfermagem no transplante hepático. In: CURSINO, M. R. et al. Assistência de enfermagem em pediatria. São Paulo: Sarvier, 1992. p. 158- 66.

16. NATIONAL INSTITUTES OF HEALTH. Consensus Development Conference Statament: Liver Transplantation, 1983. Hepatology, v. 4, n. 1, p. 107S-10S, 1984. Suplement.

17. OMERY, A.; CASWELL, D. A nursing perspective of the ethical issues surrounding liver transplantation. Heart Lung, v. 17, n. 6, p. 62631, 1988.

18. POLLAK, R.; WIEDERKEHR, J.C. Transplante hepático. In: COELHO, J.C.U. Aparelho digestivo: clínica e cirurgia. 2. ed. Rio de Janeiro: MEDSI, 1996. v. 2, cap. 108, p. 1233-41. 